\title{
Establecimiento de un sistema silvopastoril con Sambucus peruviana
}

\author{
Establishment of a silvopastoral system with Sambucus peruviana
}

\section{Estabelecimento de um sistema silvipastoril com Sambucus peruviana}

\author{
Soto Monroy Miguel Ángel ${ }^{1}$ y Sánchez Moreno Hugo Vladimir ${ }^{2}$ \\ ${ }^{1}$ Médico Veterinario Zootecnista, Universidad de los Llanos y \\ ${ }^{2}$ Médico Veterinario Zootecnista Esp, MSc. Grupo de Agroforestería \\ vladimirsanchez@unillanos.edu.co
}

Recibido 18 de Abril 2017, Aceptado 30 de Agosto 2018

\section{RESUMEN}

El proyecto se desarrolló en el municipio de Tuta, Departamento de Boyacá, Colombia. Se seleccionaron diez fincas y se entregó a cada propietario entre 168 a 490 árboles de Sambucus peruviana para que fueran usados como cercas vivas o banco forrajero. Las plantas se propagaron en vivero por medio de estacones, durante 90 días, posteriormente fueron transportadas a cada finca seleccionada, para proceder con la respectiva siembra, la cual se realizó en época de lluvias, para dicha actividad se cavaron huecos de $30 \mathrm{~cm}$ de diámetro con $40 \mathrm{~cm}$ de profundidad; en algunos predios se sembraron como banco forrajero y en otras fincas como cerca viva. Una vez sembrados los árboles se tomaron medidas de altura, observando los la mortalidad y la supervivencia en cada una de las fincas durante los primeros 60 días de siembra, y se continuó la evaluación y seguimiento de la altura de los árboles a los 60 y 120 días. Durante seis meses, simultáneamente se capacitó a los productores pecuarios de la región, donde se explicó la importancia los sistemas silvopastoriles, estas capacitaciones favorecieron el interés de los productores por establecer la especie en la región, puesto que se observaron los mejores resultados en términos de supervivencia y crecimiento en los predios donde los productores cumplieron con las instrucciones impartidas. Además, los sistemas establecidos han servido de modelo para que otros productores inicien el proceso de adopción. Las condiciones climatológicas y el consumo del árbol por los animales, debido a su alta 
palatabilidad o por falla en la cerca, fueron factores determinantes en el establecimiento del sistema silvopastoril.

Palabras clave: Alimentación, suplementación, ramoneo, cultivo, banco forrajero.

\begin{abstract}
The project was developed in the municipality of Tuta, Department of Boyacá, Colombia. Ten farms were selected and each owner was given between 168 to 490 trees of Sambucus peruviana to be used as live fences or forage bank. The plants were propagated in nursery by means of stables, during 90 days, later they were transported to each selected farm, to proceed with the respective planting, which was carried out in the rainy season, for this activity holes of $30 \mathrm{~cm}$ in diameter with $40 \mathrm{~cm}$ depth were drilled; in some farms they were planted as fodder bank and in other as living fence. Once the trees were planted, height measurements were taken, observing the mortality and survival in each one of the farms during the first 60 days of planting, and the evaluation and monitoring of the height of the trees at 60 and 120 days was continued. For six months, simultaneously livestock producers in the region were trained, where the importance of silvopastoral systems was explained, these trainings favored the interest of the producers to establish the species in the region, since the best results in terms of survival and growth were observed in the farms where the producers complied with the instructions given. In addition, the established systems have served as a model for other producers to initiate the adoption process. The climatic conditions and the consumption of the tree by the animals, due to its high palatability or fence failure, were determining factors in the establishment of the silvopastoral system.
\end{abstract}

Keywords: Feeding, supplementation, browse, cultivation, forage bank.

\title{
RESUMO
}

O projeto foi desenvolvido no município de Tuta, departamento de Boyacá, Colômbia. Dez fazendas foram selecionadas e cada proprietário recebeu entre 168 e 490 árvores de Sambucus peruviana para serem usadas como cercas vivas ou 
banco de forragem. As plantas foram propagadas em viveiro por meio de estábulos, durante 90 dias, depois foram transportadas para cada fazenda selecionada, para prosseguir com o respectivo plantio, que foi realizado na estação chuvosa, para esta atividade foram cavados buracos de $30 \mathrm{~cm}$ de diâmetro com $40 \mathrm{~cm}$ de profundidade; em algumas fazendas eles foram plantados como banco de forragem e em outras como cerca viva. Uma vez que as árvores foram plantadas, foram tomadas medidas de altura, observando a mortalidade e sobrevivência em cada uma das fazendas durante os primeiros 60 dias de plantio, e continuou a avaliação e monitoramento da altura das árvores aos 60 e 120 dias. Durante seis meses, simultaneamente os produtores de gado da região foram treinados, onde foi explicada a importância dos sistemas silvipastoris, esses treinamentos favoreceram o interesse dos produtores em estabelecer as espécies na região, já que os melhores resultados em termos de sobrevivência e crescimento foram observados nas fazendas onde os produtores cumpriram as instruções dadas. Além disso, os sistemas estabelecidos têm servido de modelo para outros produtores iniciarem o processo de adoção. As condições climáticas e o consumo da árvore pelos animais, devido a sua alta palatabilidade ou falha na cerca, foram fatores determinantes no estabelecimento do sistema silvipastoril.

Palavras-chave: Alimentação, suplementação, ramonear, cultivo, banco de forragem.

\section{INTRODUCCIÓN}

La producción pecuaria en el municipio Tuta, Boyacá, Colombia, actualmente está enfocada a la ganadería doble propósito, actividad económica de gran importancia para la población rural, quienes son personas de escasos recursos que tienen como única fuente de ingresos la venta de terneros y leche cruda. Las razas predominantes son: Normando y Holstein, siendo la primera la que mejor se adapta a las condiciones topográficas del terreno, aceptando de manera adecuada las pasturas tradicionales con kikuyo (Pennisetum clandestinum). Además, en esta zona se han disminuido la actividad agrícola contando con suelos de valles fértiles a lo largo de los ríos, teniendo como ventaja comparativa su cercanía a grandes 
ciudades como Tunja y Bogotá, por lo cual ha tomado fuerza la comercialización de leche. Es importante señalar que los nuevos retos con los que se enfrenta el sector pecuario en Colombia obliga a ser competitivo, por lo tanto, es urgente modificar y cambiar este panorama en el municipio de Tuta, para continuar con una producción doble propósito con sistemas sustentables y sostenibles, desde el punto de vista económico y ambiental respectivamente (AMT, 2012).

En Tuta los bovinos se encuentran en pasturas con baja productividad y calidad nutricional, la comunidad tiene conocimientos mínimos sobre prácticas de manejo adecuado de praderas, por lo cual manejan una alta carga animal con pastoreo intenso que termina por afectar la calidad y producción de biomasa. Además, en la mayoría de las veredas de este municipio fue cultivada la cebada de manera permanente, sin implementar rotación de cultivos, lo cual conllevó a la degradación de los suelos, con baja presencia de árboles, sumado a la variabilidad de las condiciones agroclimáticas, con largos periodos de lluvias y sequía (MADR, 2013).

La producción agropecuaria se ha enfrentado a la tala y quema indiscriminada de árboles, ocasionadas por el hombre o por las altas temperaturas, presentándose incendios forestales, cambiando las condiciones climáticas, que en general contribuyen con el calentamiento global, lo cual se ve representado en las praderas con baja capa vegetal y mínima presencia de árboles como se observa en las veredas del municipio de Tuta: Alizal y Hacienda, siendo sus suelos muy susceptibles para una erosión futura. Los indicadores económicos y productivos de la ganadería en Tuta son muy deficientes, puesto que los animales tienen una baja condición corporal 2.5/5, con intervalos entre parto de hasta 16 meses, producción promedio día cinco litros de leche y terneros destetos de 16 meses con pesos entre 160 a $180 \mathrm{~kg}$ aproximadamente (MADR, 2013).

Teniendo en cuenta lo anteriormente descrito, surge como alternativa la implementación de diez sistemas silvopastoriles para alimentación y suplementación del ganado bovino en el Municipio de Tuta, el propósito es mejorar la cantidad y la calidad de forraje en proteína y energía, enfocando estos sistemas hacia servicios ambientales, restauración de suelos, agro forestación, conservación 
del agua, y además proporcionando cercas vivas y barreras rompe vientos, y de esta forma, dar un buen manejo silvopastoril con el fin de aumentar las producciones en cada uno de sus ciclos o etapas productivas en la que se encuentren los animales. Para lograr esto se promovió entre los productores, capacitaciones en el establecimiento de sistemas silvopastoriles con tilo (Sambucus peruviana), registrando el comportamiento de este árbol bajo las condiciones edafoclimáticas del municipio de Tuta (Boyacá). Lo anterior se sustenta con los trabajos realizados por Fajardo y Gómez, (2015) que suplementaron vacas lecheras con harina de tilo con edad de 120 días, observando un aumento en la producción de leche en dos litros/día por vaca.

El sistema de silvopastoreo se conoce como un modelo de agroforestería que puede ser utilizado en producción pecuaria, que con pastos mejorados de alto vigor y productividad, pueden fortalecer un programa de alimentación para el ganado, como por ejemplo: falsa poa (Holcus lanatus), Kikuyo (Pennisetum clandestinum) trébol rojo y blanco (Trifolium pratense y Trifolium repens), que asociados con los componentes tradicionales como animales, plantas forrajeras nativas y herbáceas, se puede lograr un manejo de programas nutricionales de manera integral, con suministro de energía y proteína (Uribe et al., 2011).

Una de las especies arbóreas más usada es el tilo, así como los árboles que generalmente se utilizan para dar sombra al ganado y sirven para la producción de leña, extracción de madera y postes; también se puede involucrar en bancos de proteína, cercas vivas y asociados con árboles frutales, o a pasturas naturales 0 mejoradas (IICA, 2016). El tilo es un árbol o arbusto forrajero de 3 a 6 metros de alto, su tronco suele ser torcido con copa irregular con hojas de color verde claro característico de los árboles jóvenes, sus tallos son tiernos y poco resistentes porque tienen una medula esponjosa, las hojas miden de 4 a $16 \mathrm{~cm}$ de largo y de 3 a $7 \mathrm{~cm}$ de ancho, son pecioladas, imparipinnadas, opuestas y ovalo-lanceoladas que miden entre 10 y $13 \mathrm{~cm}$ de largo y entre 3 y $5 \mathrm{~cm}$ de ancho, sus flores son aromáticas y muy pequeñas de color blanco amarillento, que forman una especie de sombrilla, su fruto es redondo de color negro violáceo y de sabor agradable, que 
mide entre 3 y $5 \mathrm{~mm}$ de diámetro con 3 semillas en su interior (Blanco et al., 2005; Grandtner y Chevrette, 2013) (Figura 1).

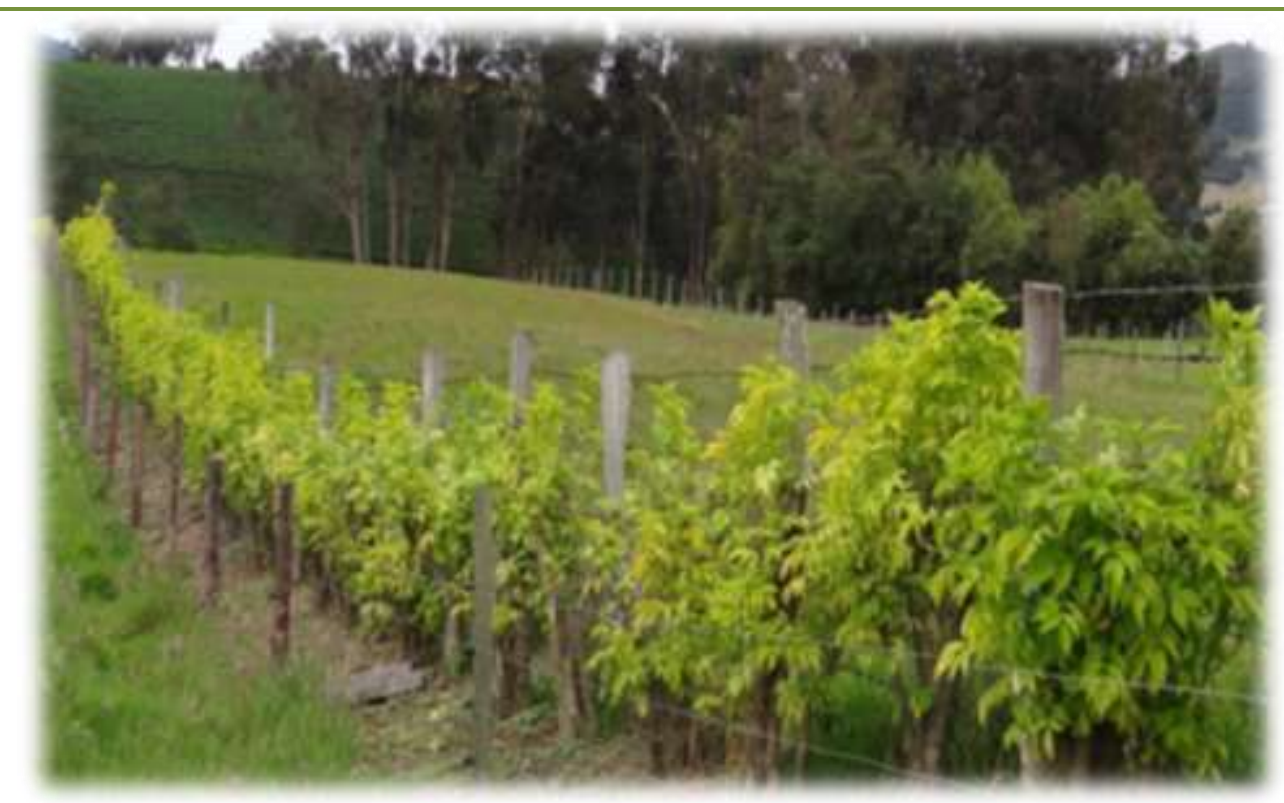

Figura 1. Sistema silvopastoril en cercas vivas con Sambucus peruviana en Tuta Boyacá

Las ventajas que tiene este árbol forrajero son adaptación a todos los suelos, proporciona sombrío durante las elevadas temperaturas, su follaje tiene un $23.36 \%$ de proteína que lo convierte en un excelente suplemento capaz de reemplazar el concentrado que se proporciona al ganado, y tiene buena producción de biomasa verde durante toda la época del año (Cárdenas et al., 2011).

\section{ACTIVIDADES PLANEADAS}

El proyecto se desarrolló en el municipio de Tuta que pertenece a la provincia centro del Departamento de Boyacá, Colombia. Su zona poblada está localizada a los $05^{\circ}$ $41^{\prime} 36^{\prime \prime}$ de latitud norte y $73^{\circ} 13^{\prime} 51^{\prime \prime}$ de longitud oeste. Tiene ocho veredas y el sector urbano, ubicado a una altura de $2600 \mathrm{msnm}$, con temperatura media de $14^{\circ} \mathrm{C}$ y precipitación anual promedio de $935 \mathrm{~mm}$.

Para la ejecución de este proyecto se seleccionaron diez fincas, donde se entregó a cada propietario entre 168 y 490 árboles de tilo, dependiendo del área de la finca, 
con el fin de ser usados como cercas vivas o banco forrajero, se realizaron medidas de altura y supervivencia después de la siembra. Las fincas están ubicadas en las veredas: San Nicolás, Leonera, Hacienda Regencia y Sector el Salival. Para la selección de las fincas se consideró lo siguiente; potreros, cercas, estado del pasto kikuyo, reservorios de agua, tipo de suelo, siendo el ideal franco-arenoso, el cual es óptimo para la siembra del tilo.

Las plantas a sembrar se propagaron en el vivero del municipio por medio de estacones durante 90 días, después de este tiempo fueron transportadas a cada finca seleccionada para proceder a la respectiva siembra, la cual se realizó en época de lluvias, aunque en algunas zonas no hubo precipitaciones por los cambios climáticos. Se hicieron huecos de $30 \mathrm{~cm}$ de diámetro con $40 \mathrm{~cm}$ de profundidad, sembrando en surcos de $2 \mathrm{~m}$ entre plántulas, ubicadas alrededor de las cercas de cada potrero, y en algunos predios se sembraron como banco forrajero estableciendo su respectiva protección con cerca de corriente eléctrica o con alambre de púas, esto con el fin de garantizar el cuidado y la protección del árbol. Una vez sembrados los árboles se tomaron las medidas, observando los primeros 60 días la mortalidad y la supervivencia en cada una de las diez fincas, y posteriormente se hizo la evaluación y seguimiento de la altura de los árboles a los 60 y 120 días. Simultáneamente durante seis meses se realizaron capacitaciones periódicas a los productores pecuarios de la región, en las cuales se explicaba la importancia de los sistemas silvopastoriles, además se realizaron visitas a cada finca para realizar un adecuado seguimiento y toma de la información sobre el establecimiento de este sistema.

\section{CAPACITACIONES}

La primera capacitación se realizó en la alcaldía y trató acerca de los conceptos de los sistemas silvopastoriles con tilo y otros árboles que se emplean para este fin, sus cuidados, ventajas de siembra, recomendaciones para el cuidado de plantas establecidas para el nuevo sistema, rotación de praderas con cerca eléctrica, implementación de cercas perimetrales para garantizar la protección de los árboles 
del consumo directo de animales antes del tiempo de poda, plateo o quema del pasto alrededor de los árboles sembrados.

La segunda capacitación se realizó en cada una de las fincas seleccionadas, con el fin de definir qué tipo de sistema se utilizaría: sí el de cercas vivas o banco de proteína, indicando que la distancia de siembra era de $2.5 \mathrm{~m}^{2}$ para banco te proteína y 2.5 a $3 \mathrm{~m}$ para cercas vivas, todo esto dependiendo de la topografía del terreno. Además, se hizo énfasis en los requisitos para la siembra de cercas perimetrales, abono orgánico disponible, y para disminuir los costos se aconsejó utilizar materias primas disponibles en cada una de las fincas. También se indicó las dimensiones de los huecos, $40 \mathrm{~cm}$ de profundidad y $30 \mathrm{~cm}$ de ancho, y para cada árbol disponer de 0.5 a $1 \mathrm{~kg}$ de abono orgánico, para lo cual se utilizó estiércol de ganado, cabras ovinos, o conejos y en algunos predios humus, también se dieron las indicaciones de almacenamiento en un lugar fresco donde no se mojaran, y se indicó que cada tres días se revolviera con pala, dándole vuelta para hacer partículas más pequeñas e ir mezclándolo con cal dolomita de 4 a $5 \mathrm{~kg}$ para $50 \mathrm{~kg}$ de abono agónico. Además, se indicó cómo hacer plateo alrededor de los árboles sembrados.

Se explicó las ventajas de implantar este sistema en la finca como nueva alternativa de alimentación para el ganado, el uso de las hojas para suministrarlas al ganado, bien sea para ramoneo, o elaborar ensilajes o convertirlas en harina. Se resaltó que los árboles de tilo tienen un rápido crecimiento proporcionando una buena producción de forraje en tiempos de verano y que sus hojas contienen alto nivel de proteína, siendo un árbol de fácil propagación por lo cual se puede producir un buen número de árboles, es resistente a heladas, generando un efecto sombrilla que disminuye impacto de éstas hasta un $80 \%$ permitiendo aumentar el periodo de pastoreo durante más tiempo en esta época crítica (Figura 2).

Se explico acerca de la importancia de rotar y renovar las praderas, manejando el pasto como cultivo, cuidando el suelo y sus condiciones físicas y químicas, puesto que en algunas fincas los terrenos fueron degradados por el exceso de maquinaria agrícola y la intensificación del pastoreo sin ningún control. Además, se capacitaron a los productores sobre cómo realizar aforos y estimar la producción de biomasa 
por área y de esta forma, ellos pudieron predecir el requerimiento de forraje de acuerdo al número de animales en cada finca.

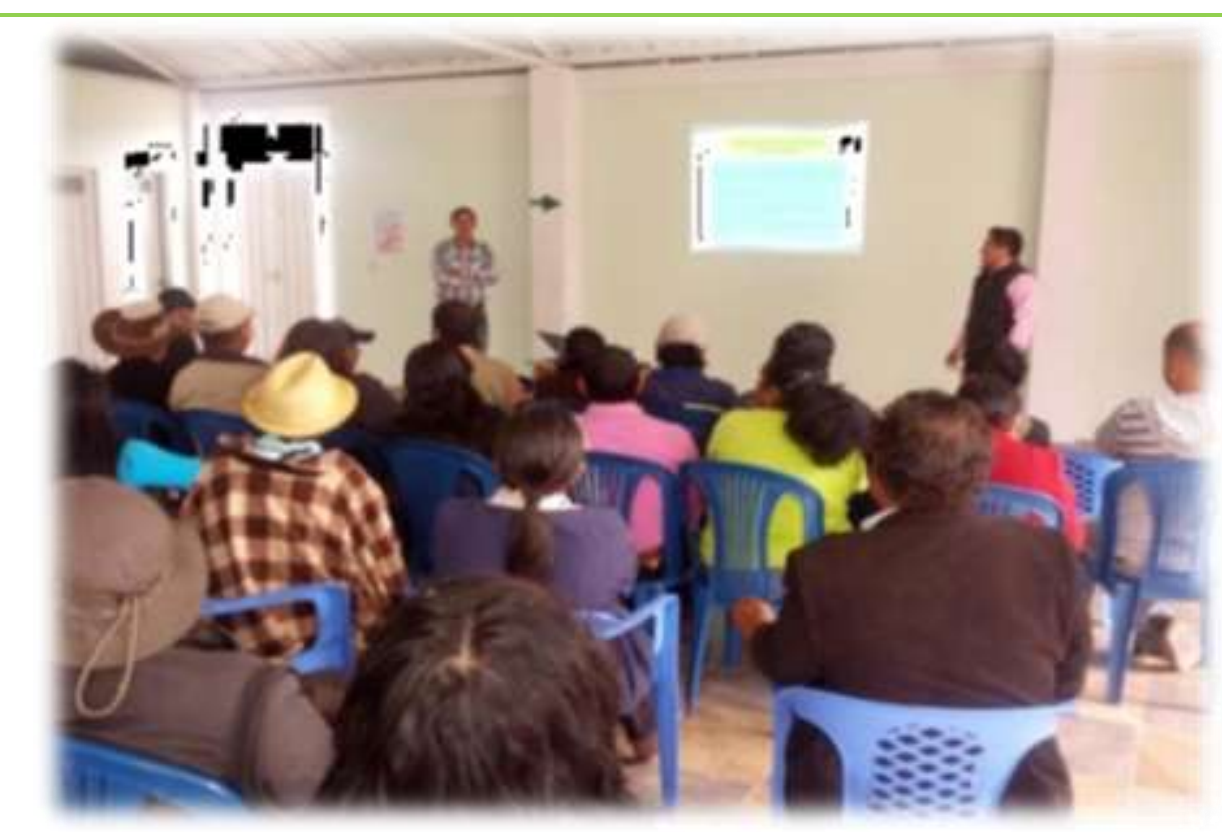

Figura 2. Las capacitaciones se enfocaron en la manera de implementar un sistema silvopastoril

\section{SIEMBRA EN VIVERO}

La propagación del material vegetativo fue por estacones de tilo de 20 a $30 \mathrm{~cm}$ de largo podados de árboles adultos, luego se procedió a hidratarlos por cinco días, lo cual se realizó en canecas plásticas con 10 litros de agua, transcurrido este tiempo se sembraron en bolsas de un $\mathrm{kg}$, que previamente se habían llenado con tierra y cascarilla de arroz. Luego de colocar los estacones en bolsas, se inició el riego todos los días en la mañana y tarde para garantizar su prendimiento, para favorecer nuevos rebrotes se fertilizó cada ocho días con $100 \mathrm{~g}$ de triple 15, diluidos en 20 litros de agua y se aplicó por aspersión con bomba de espalda (Figura 3).

Se sembraron 700 estacones de tilo por semana, hasta obtener el material suficiente para entregar a las fincas seleccionadas, lo cual tomó aproximadamente dos meses, al cabo de este tiempo fue entregando el material prendido, garantizando así el éxito de su prendimiento y desarrollo en campo (Figura 4). 


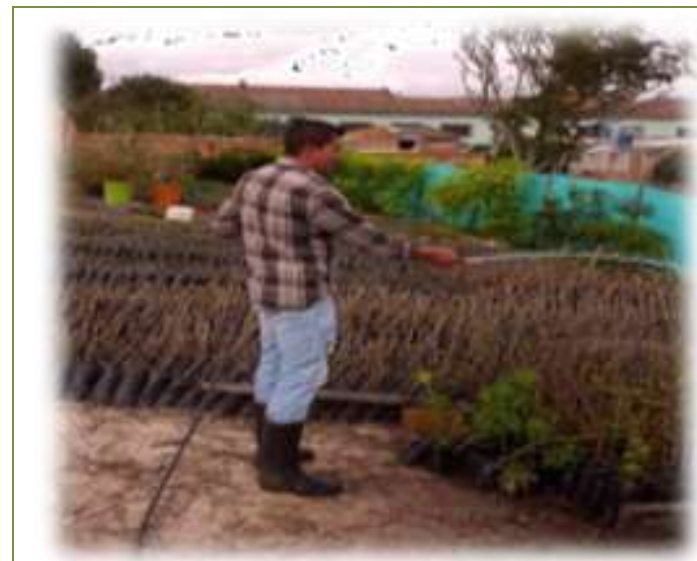

Figura 3. Riego de las estacas dos veces por días

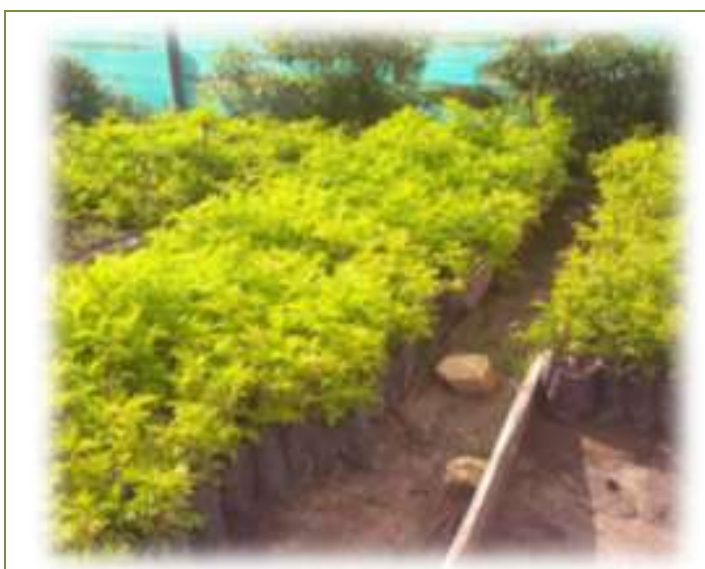

Figura 4. Estacas prendidas para sembrar en fincas

\section{RESULTADOS EN CAMPO}

Las estacas de tilo fueron sembradas en las siguientes fincas: La Esperanza, La Ilusión, El Columpio, El Llanito, María Juana, La Manga, Las Amapolas, Santa Rita, Quinta Padilla y La laguna, en dicho momento las plantas tenían una altura promedio de $27.4 \mathrm{~cm}$ (Gráfica 1).

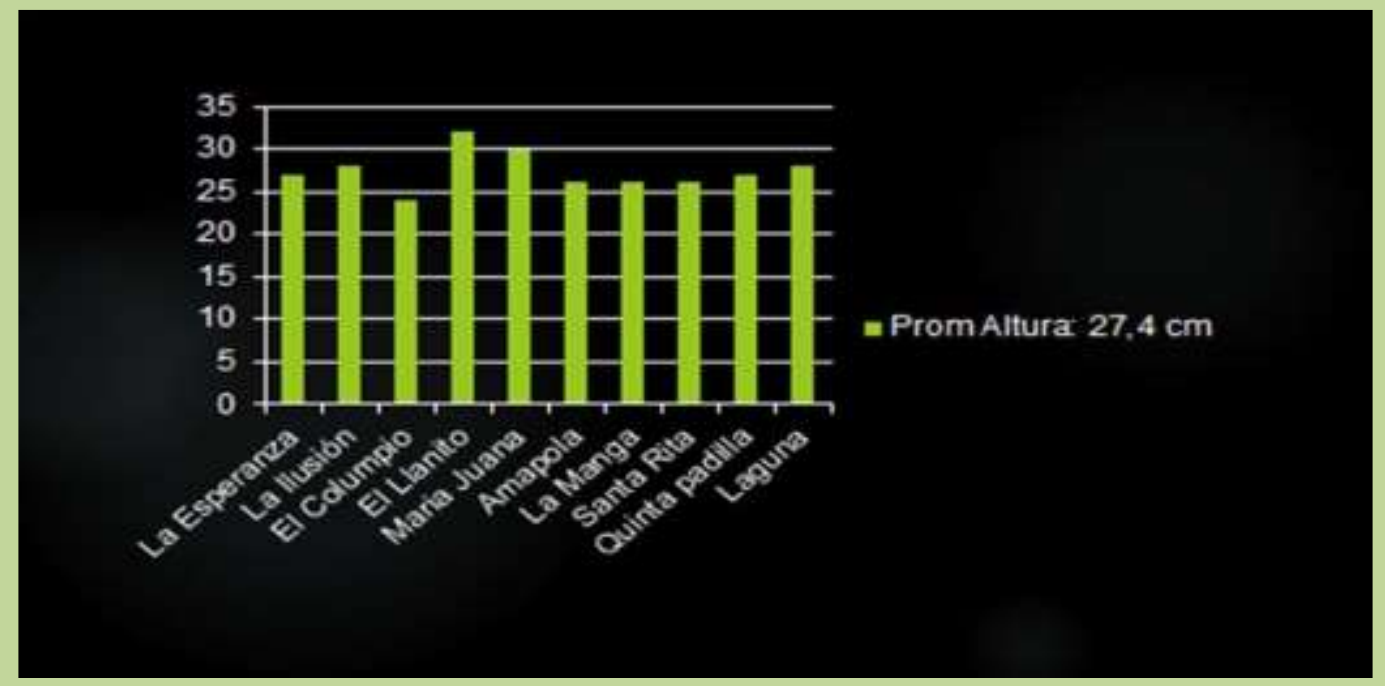

Gráfica 1. Altura de las plántulas $(\mathrm{cm})$ entregadas a cada finca para la implementación del sistema silvopastoril en Tuta Boyacá 
Para la siembra en campo como se siguieron las indicaciones dadas en las capacitaciones. Se cavaron los huecos de las dimensiones mencionadas anteriormente, y antes de realizar la siembra del árbol en campo, se les colocó el abono orgánico con cal dolomita mezclando $5 \mathrm{~kg}$ para un bulto de $50 \mathrm{~kg}$ de abono (Figura 5). Cuando el sistema era para bancos forrajeros la distancia entre plantas fue de $2.5 \mathrm{~m}^{2}$ y para el sistema de cercas vivas $3 \mathrm{~m}$ al lado de la cerca (Figura 6).

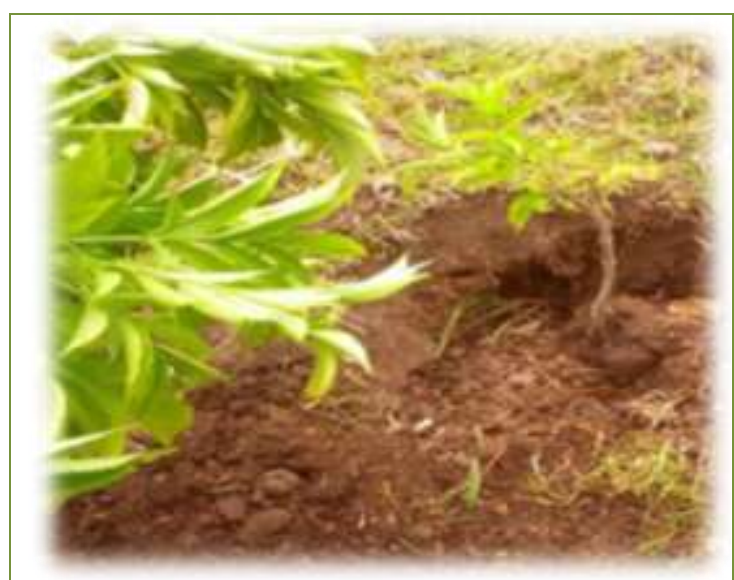

Figura 5. Siembra de los árboles de tilo posterior al abonado

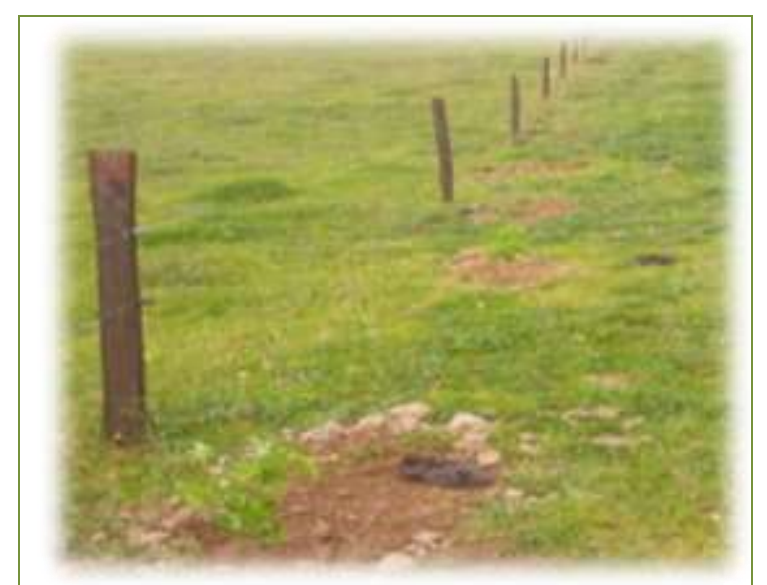

Figura 6. Siembra de árboles de tilo para cerca viva

A los 60 y 120 días de siembra se contabilizó el número de árboles vivos y se hicieron las medidas de altura en las diez fincas seleccionadas (Figura 7). Hubo pérdida árboles porque se secaron después de ser sembrados debido a condiciones ambientales o daño causado por el ganado, los cuales fueron remplazados en su totalidad para cada una de las fincas, cabe resaltar que en la vereda La Hacienda no llueve igual en comparación con las otras zonas, donde fueron sembrados los árboles de tilo, condiciones que influyeron en el normal desarrollo y crecimiento de las plantas (Figura 8). El promedio de supervivencia de los árboles a los 60 días de sembrados fue $93.5 \%$ (Gráfica 2), y entre los 60 a 120 días no se registró mortalidad de los árboles (Tabla 1), aunque si hubo pérdida de arbustos que, por su alta palatabilidad y falta de pasturas, se estimuló su consumo por parte de los animales, pero se debe mencionar que también influyó la adecuación de cercas perimetrales, puesto que algunas quedaron muy cerca de los árboles (menos de $1 \mathrm{~m}$ ). Debido a 
las condiciones de clima seco en algunas fincas fue necesario colocar sistema de riego por goteo.

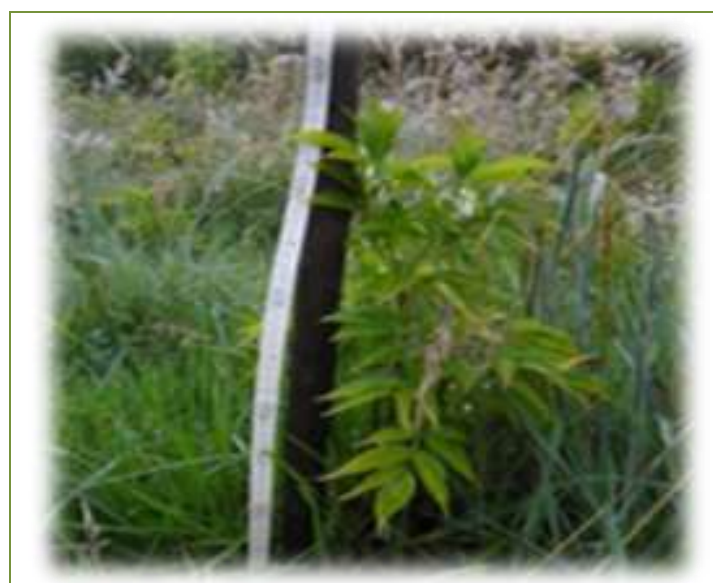

Figura 7. Medida de la altura de los árboles de tilo en Tuta Boyacá

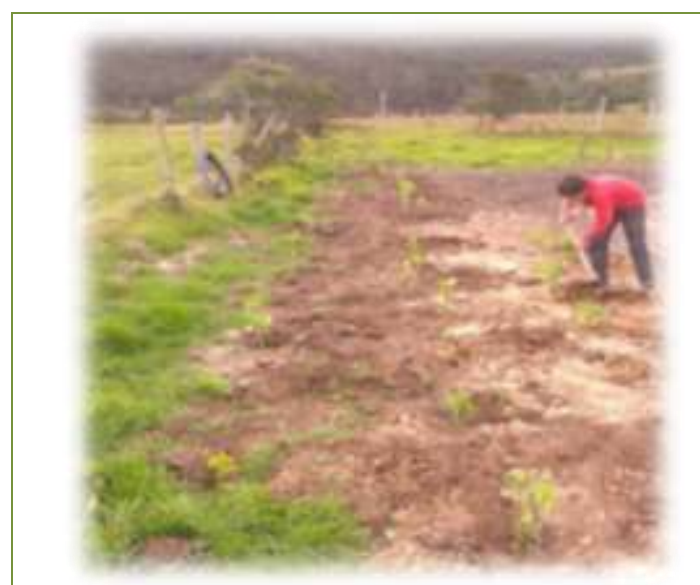

Figura 8. Banco de proteína con los árboles de tilo

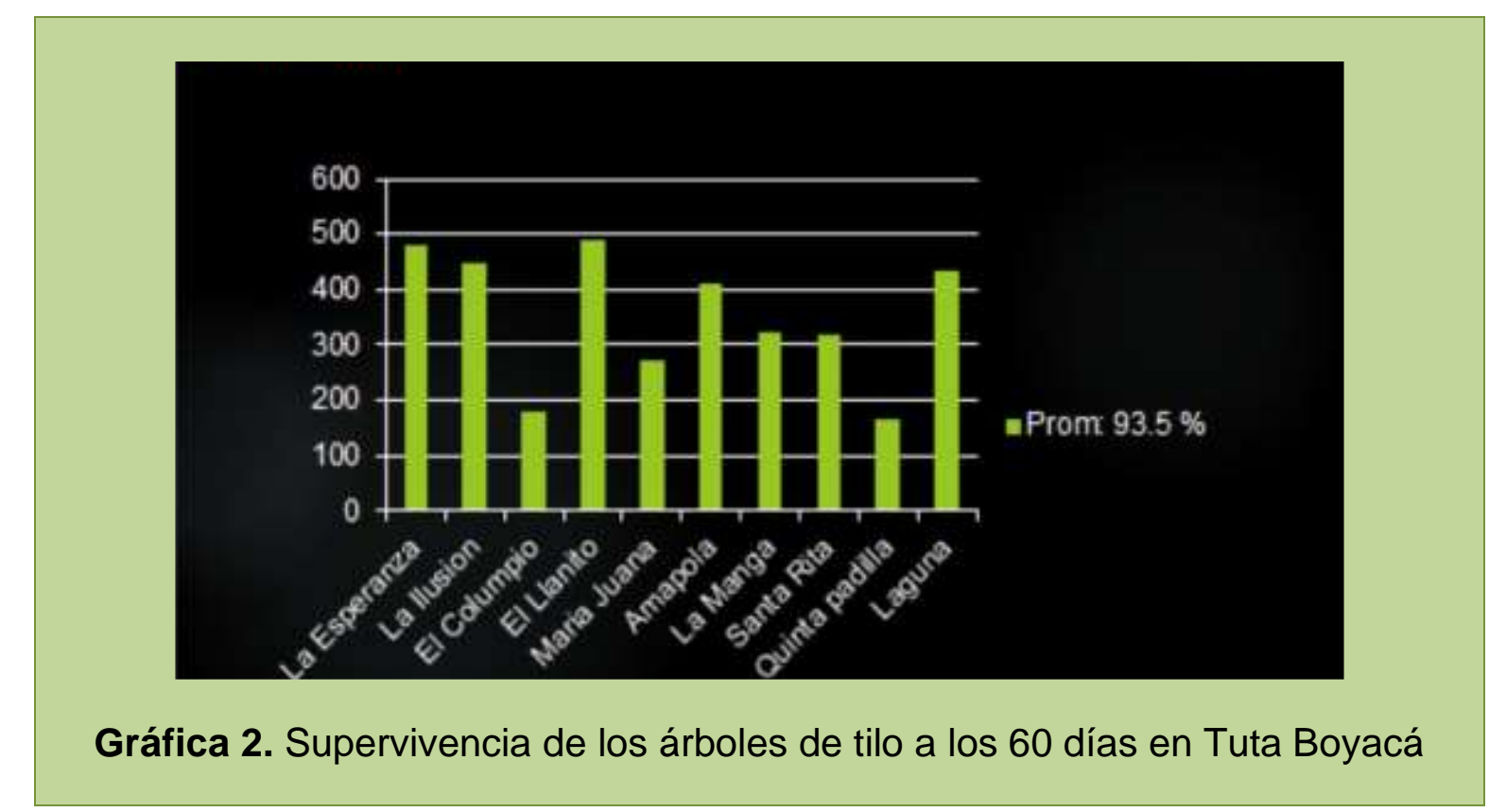

El tilo es también llamado sauco en Perú, lugar de donde se originó, tiene un amplio rango altitudinal para que su adecuado desarrollo, el cual va desde los 2800 hasta los 3900 msnm, preferiblemente en suelos franco limosos (Castañeda et al., 2016), Tuta está ubicada a una altura promedio de $2600 \mathrm{msnm}$ y posee suelos franco arenosos, condiciones que favorecieron en parte, el desarrollo de este árbol en sus 
primeras etapas (Tabla 2), aunque es una especie poco exigente en suelos, su crecimiento fue mejor en las fincas en donde se utilizó el humus, en comparación con aquellas donde se abonó con estiércol y se preparó su propio fertilizante. Es importante señalar que se requiere de buena humedad (riego), lo cual fue una dificultad por la época en la que fueron sembrados los arboles de tilo, tanto así que en algunas fincas fue necesario colocar riego por goteo, de tal forma que se disminuyó la tasa de crecimiento de la planta con relación al tiempo, haciéndola más lenta (Calle et al., 2009).

Tabla 1. Supervivencia a los 120 días de los árboles sembrados en las finca en Tuta Boyacá

\begin{tabular}{cccc}
\hline Finca & $\begin{array}{c}\text { Árboles } \\
\text { sembrados }\end{array}$ & $\begin{array}{c}\text { Árboles que no } \\
\text { prendieron }\end{array}$ & $\begin{array}{c}\text { Porcentaje de } \\
\text { mortalidad (\%) }\end{array}$ \\
\hline La Esperanza & 479 & 26 & 5.4 \\
La llusión & 450 & 32 & 7.1 \\
El Columpio & 180 & 25 & 13.9 \\
El Llanito & 490 & 10 & 2.0 \\
María Juana & 270 & 19 & 7.0 \\
La Manga & 325 & 29 & 8.9 \\
Las Amapolas & 410 & 23 & 5.6 \\
Santa Rita & 320 & 25 & 7.8 \\
Quinta Padilla & 168 & 21 & 12.5 \\
La Laguna & 432 & 14 & 3.2 \\
Total & $\mathbf{3 4 2 4}$ & $\mathbf{2 2 4}$ & $\mathbf{6 . 5}$ \\
\hline
\end{tabular}

El agua es uno de los factores más importantes para el desarrollo de las plantas, su carencia constituye una de las principales fuentes de estrés, por lo cual muchas plantas han desarrollado respuestas que les permiten tolerar diferentes niveles de déficit de agua, que van desde un estrés hídrico leve, causado por la disminución del potencial hídrico al mediodía, hasta aquellas que les permiten sobrevivir en ambientes desérticos; estas respuestas incluyen modificaciones en el crecimiento y cierre de estomas (Shao et al., 2008). 
Tabla 2. Altura $(\mathrm{cm})$ de los árboles de tilo sembrados en fincas de Tuta Boyacá

\begin{tabular}{cccc}
\hline Finca & Altura 60 días & Altura 120 días & Crecimiento \\
\hline La Esperanza & 56.7 & 86.4 & 29.7 \\
La llusión & 54.4 & 80.8 & 26.4 \\
El Columpio & 55.1 & 86.2 & 31.1 \\
El Llanito & 57.7 & 83.4 & 25.7 \\
María Juana & 53.9 & 77.8 & 23.9 \\
La Manga & 44.6 & 63.2 & 18.6 \\
Las Amapolas & 46.7 & 67.4 & 20.7 \\
Santa Rita & 46.8 & 67.6 & 20.8 \\
Quinta Padilla & 50.9 & 74.8 & 23.9 \\
La Laguna & 52.9 & 77.8 & 24.9 \\
Promedio & $\mathbf{5 1 . 9}$ & $\mathbf{7 6 . 5}$ & $\mathbf{2 4 . 6}$ \\
\hline
\end{tabular}

\section{CONCLUSIONES Y RECOMENDACIONES}

Las capacitaciones ofrecidas a los productores favorecieron el interés por establecer la especie en un sistema silvopastoril favoreciendo los recursos naturales de la región, observándose los mayores valores en términos de sobrevivencia y crecimiento de las plantas, en los predios donde los productores cumplieron con las instrucciones impartidas. Además, el establecimiento de las plantas fue mejor en las fincas donde se utilizó fertilizante orgánico comercial, en comparación con aquel que se preparó en los predios.

Las condiciones climatológicas en algunas zonas con baja precipitación, en parte causados por los cambios climáticos, y el consumo del árbol de tilo por los animales debido a su alta palatabilidad o por falla en la cerca, fueron determinantes en la pérdida de plantas en el proceso de establecimiento.

Los sistemas establecidos, han servido de modelo para que otros productores inicien el proceso de adopción. 
Una vez establecidos los sistemas en las fincas seleccionadas, se recomienda iniciar trabajos de investigación sobre el consumo y ganancias en carne y leche.

\section{REFERENCIAS BIBLIOGRÁFICAS}

1. Alcaldía Municipal de Tuta (AMT). Plan de desarrollo 2012-2015 "Pasos firmes hacia el progreso". Alcaldía de Tuta, Tuta, Colombia. 253 p. 2012.

2. Blanco G.M., Chamorro D.R., Arreaza L.C. Predicción de la respuesta productiva en bovinos lecheros suplementados con ensilaje de Sambucus peruviana, Acacia decurrens y Avena sativa usando el modelo Cornell Net Carbohydrate and Protein System (CNCPS). Corpoica. Ciencia y Tecnología Agropecuaria. 6 (2): 86-90. 2005.

3. Calle Z., Naranjo J., Murgueitio R. El tilo: puerta de entrada a los silvopastoriles en el trópico alto, Carta Fedegan, (110): 118-125. 2009. Disponible En: https://docplayer.es/36916867-El-tilo-puerta-de-entrada-a-los-silvopastoriles-en-eltropico-alto.html

4. Cárdenas C.A., Rocha C., Mora J.R. Productividad y preferencia de forraje de vacas lecheras pastoreando un sistema silvopastoril intensivo de la zona alto Andina de Roncesvalles, Tolima. Revista Colombiana de Ciencia Animal. 4 (1): 29-35. 2011.

5. Castañeda N.P., Álvarez F., Arango J., Chanchy L., García G.F., Sánchez V., Solarte A., Sotelo M., Zapata C. Especies vegetales útiles para sistemas silvopastoriles del Caquetá, Colombia. Deutsche Gesellschaft für Internationale Zusammenarbeit (GIZ) $\mathrm{GmbH}$; Centro Internacional de Agricultura Tropical (CIAT), Cali, Colombia. 84 p. 2016.

6. Fajardo V., Gómez D. El tilo una fórmula para ahorro significativo por el concepto de la reducción de gastos en la compra de concentrados: la inclusión de la harina de Tilo en las dietas de las vacas, Página del Ganadero Fedegán - Fondo Nacional del Ganado, 261 p. 2015. Recuperado 18 Diciembre 2016]. Disponible En: http://files.fedegan.org.co/pg 31 mayo 2015.pdf

7. Grandtner M.M., Chevrette J. Dictionary of trees, volume 2: South America: Nomenclature, taxonomy and ecology. Academic Press, 1172 p. 2013.

8. Instituto Interamericano de Cooperación para la Agricultura (IICA). Establecimiento y uso de sistemas silvopastoriles en República Dominicana. Programa de préstamos para el sector agropecuario, agroindustrial y comercial. Programa de apoyo al mejoramiento de la productividad y competitividad del sector agropecuario. Ministerio de Agricultura de la República Dominicana, Santo Domingo, República Dominicana. 36 p. 2016.

9. Ministerio de Agricultura y Desarrollo Rural (MADR). Sistema de información geográfica municipal Tuta-Boyacá. Bogotá, Colombia. 20 p. 2013.

10. Navas A. Importancia de los sistemas silvopastoriles en la reducción del estrés calórico en sistemas de producción ganadera tropical. Revista de Medicina Veterinaria. (19): 113-122. 2010.

11. Shao H.-B., Chu L.-Y., Jaleel C.A., Zhao C.-X. Water-deficit stress-induced anatomical changes in higher plants. Comptes Rendus Biologies. 331 (3): 215-225. 2008.

12. Taiz L., Zeiger E. Plant physiology. Sinauer Associates Sunderland, MA. 2006.

13. Uribe F., Zuluaga A., Murgueitio E., Valencia L., Zapata A., Solarte L., Cuartas C., Naranjo J., Galindo W., Gonzáles J., Sinisterra J., Gómez J., Molina C., Molina E., Galindo A., Galindo V., Soto R. Establecimiento y manejo de sistemas silvopastoriles. Manual 1. Proyecto Ganadería Colombiana Sostenible GEF, BANCO MUNDIAL, FEDEGAN, CIPAV, FONDO ACCIÓN, TNC, Bogotá, Colombia. 78 p. 2011. 